University of Nebraska - Lincoln

DigitalCommons@University of Nebraska - Lincoln

Faculty Publications from Nebraska Center for Research on Children, Youth, Families, and Schools
Children, Youth, Families \& Schools, Nebraska Center for Research on

$7-2010$

\title{
Attitudes and Beliefs of Marriage and Family Therapists Regarding Psychotropic Drugs and Therapy
}

\author{
Paul R. Springer \\ University of Nebraska - Lincoln, pspringer3@unl.edu \\ Steven M. Harris \\ University of Minnesota, smharris@umn.edu
}

Follow this and additional works at: https://digitalcommons.unl.edu/cyfsfacpub

Part of the Pre-Elementary, Early Childhood, Kindergarten Teacher Education Commons

Springer, Paul R. and Harris, Steven M., "Attitudes and Beliefs of Marriage and Family Therapists Regarding Psychotropic Drugs and Therapy" (2010). Faculty Publications from Nebraska Center for Research on Children, Youth, Families, and Schools. 21.

https://digitalcommons.unl.edu/cyfsfacpub/21

This Article is brought to you for free and open access by the Children, Youth, Families \& Schools, Nebraska Center for Research on at DigitalCommons@University of Nebraska - Lincoln. It has been accepted for inclusion in Faculty Publications from Nebraska Center for Research on Children, Youth, Families, and Schools by an authorized administrator of DigitalCommons@University of Nebraska - Lincoln. 


\title{
Attitudes and Beliefs of Marriage and Family Therapists Regarding Psychotropic Drugs and Therapy
}

\author{
Paul R. Springer \\ Assistant Professor, Department of Child, Youth and Family Studies, Marriage and Family Therapy Program, \\ P.O. Box 830801, University of Nebraska-Lincoln; 68583-0801. \\ Corresponding author: email pspringer3@unl.edu \\ Steven M. Harris \\ Texas Tech University \\ Current affiliation: Professor, Marriage and Family Therapy Program, \\ Department of Family and Social Sciences, University of Minnesota
}

\begin{abstract}
Clinical members of AAMFT were solicited by means of a randomized multi-staged clustering technique to identify their attitudes and beliefs regarding psychotropic drugs. All participants were blind to the overall purpose of the study $(n=322)$ and were directed to read a clinical vignette and then identify what course of action they would take with the client. They were then asked to complete a small questionnaire regarding their attitudes and beliefs regarding psychotropic drugs. Results of the study showed that $35.7 \%$ of the clinicians identified medication and a medication referral as a viable treatment option they might pursue with a client meeting criteria for major depressive episode. Clinicians who reported having a dedicated university class $(17.2 \%)$ in psychopharmacology were more likely to identify medication referral as a treatment option. However, $80 \%$ of the AAMFT clinicians we surveyed reported that they were not adequately trained about psychotropic medications in their graduate programs. Further implications regarding diagnostic practices are also discussed, as $26 \%$ of clinicians failed to explicitly diagnose the client in the case vignette with depression.
\end{abstract}

In 2005, Hernandez and Doherty addressed the practice patterns of marriage and family therapists (MFTs) whose clients use psychotropic medication. In this study they found that $91 \%$ of all MFTs work with clients who are on some sort of psychotropic medication, and who account for nearly a quarter of their caseload. These findings are important in light of the ambiguity in the MFT field surrounding medication as a therapeutic adjunct. In fact, it suggests that despite past negative beliefs and attitudes about psychopharmacology (Jackson, 1967; Patterson \& Magulac, 1994), MFTs do work with patients who receive psychotropic medication. However, little, if any, research examines MFTs' attitudes and beliefs in working with medicated clients. In fact, it is unknown what role MFTs take in collaborating with physicians regarding medication referrals, or even under what circumstances MFTs deem medical consultations to be appropriate (Hernandez \& Doherty, 2005).

Historically, some of our founding theorists expressed negative feelings about the appropriateness of medication (Haley, 1989; Jackson, 1967; Markowitz, 1991; Patterson \& Magulac, 1994). As a result, marriage and family therapy, as a discipline, has yet to reach a consensus regarding this topic (Hernandez \& Doherty, 2005). Even with the advent of newer and safer psychotropic drugs, as well as the emergence of strong research supporting the effectiveness of combined treatment approaches (Beitman, Blinder, Thase, Riba, \& Safer, 2003; Beitman \& Saveanu, 2005; Friedman et al., 2004; Jindal \& Thase, 2003), family thera- 
pists seem ambivalent about how helpful medication may be in therapy. In fact, Pinsof and Wynne (1995) provided compelling results in their study that MFT approaches alone are insufficient to treat various mental illnesses. Consequently, MFTs may need to look outside their theories and be willing to look at non-MFT treatments to effectively provide optimal care for their clients.

Compelling research on schizophrenia and bipolar disorders (McFarlane, Dixon, Lukens, \& Lucksted, 2003; Miklowitz \& Goldstein, 1997) has further established the benefits of developing treatment approaches that are traditionally outside of MFT approaches. These approaches implemented in the schizophrenia and bipolar research still maintain a family-based model, but they are able to effectively develop a collaborative and shared treatment approach while integrating medication and psychoeducation in a complementary way. Results of the schizophrenia and bipolar studies have shown that shared treatment approaches considerably lower relapse rates when family psychoeducation and medication interventions are promoted jointly, when compared to either individual therapy or medication alone (Baucom, Shoham, Mueser, Daiuto, \& Stickle, 1998; Miklowitz et al., 2000).

In fact, the Agency for Health Care Policy Research (AHCPR, 1993), the American Psychiatric Association (APA, 2000b), and the MacArthur Initiative on Depression (2009) have established evidence-based treatment guidelines for major depression. The results of both clinical expert consensus as well as exhaustive meta-analytic studies have demonstrated strong support for combining psychotherapy with pharmacotherapy. According to these results (AHCPR, 1993; APA, 2000b; MacArthur Initiative on Depression 2009), best practices are related to whether the depression is mild, moderate, or severe, with psychotherapy being effective when treating clients with mild to moderate depression. Despite these results, it is unclear how well educated MFTs are in non-MFT treatments, or how willing they are to participate in the coordination of combined care.

Subsequently, researchers and educators have addressed the deficiency that marriage and family therapists are faced with in psychopharmacological training. Patterson and Magulac (1994) were among the first to address therapists' lack of education and knowledge regarding psychotropic drugs and developed a seven-session graduate-level course covering the actions of psychotropic agents and offering pragmatic information about physicians and their consultation procedures.

In addition, new teaching and training emphases have emerged within many marriage and family therapy programs throughout the United States, such as Medical Family Therapy (Van Heden, 2001). These programs integrate a more biopsychosocial approach to treatment (Engel, 1977), thus highlighting the need for clinicians to be skilled and knowledgeable in psychopharmacological issues as well as collaborative practices in coordinating care (McDaniel, Hepworth, \& Doherty, 1992). Consequently, more MFTs now work in medical settings jointly with physicians to treat not only mental health, but also physical medical issues such as diabetes and chronic illnesses (McDaniel et al., 1992; Van Heden, 2001).

It was not until 2001 that the standards of the Commission on Accreditation for Marriage and Family Therapy (COAMFTE) changed to require psychopharmacological treatments to be taught (Hernandez \& Doherty, 2005). This curriculum change underscores a deficit in MFT training specifically in the area of MFTs' understanding of psychopharmacological interventions and practices.

Despite the revised COAMFTE guidelines and the development of a psychopharmacological course, uncertainty persists as to the impact of such changes on MFTs' attitudes and beliefs about psychopharmacology. It remains an open question whether MFT programs are actively educating their students about issues in psychopharmacology. A recent study addressed some of these issues by surveying students from 10 MFT programs across the country regarding their perceived training needs (Maggio, Marcotte, Perry, \& Truax, 2001). The study clearly showed that MFT students desired more emphasis on special topics, including psychotropic medication.

Not surprisingly, little research exists on the medication practices of nonmedical mental health providers (Taylor, 2004). What research has been done suggests that psychotropic drugs tend to be underused in treatment (Wells \& Sturm, 1996). It is also unclear whether nonmedical mental health providers encourage medication consultations for their clients, and if so, how this looks in practice. One study suggests that the attitudes of health care professionals play a direct role in the quality of care received by persons 
Table 1. Demographics of Clinical Members of AAMFT

\begin{tabular}{lrc}
\hline Variable & Number & Percent \\
\hline Gender & & \\
Male & 136 & 42.5 \\
Female & 184 & 57.5 \\
Race & & \\
Anglo (Caucasian) & 298 & 93.5 \\
African American & 6 & 1.9 \\
Asian American & 1 & 0.3 \\
Hispanic American & 4 & 1.3 \\
Native American & 4 & 1.3 \\
Other & 6 & 1.9 \\
Total & 319 & 100 \\
Highest degree earned & & \\
Master's & 205 & 64.1 \\
PhD & 113 & 35.3 \\
Other & 2 & 0.6 \\
Discipline & & \\
MFT & 283 & 88.7 \\
Psychology & 10 & 3.1 \\
Social Work & 10 & 3.1 \\
Counselor education & 1 & 0.3 \\
Other & 15 & 4.7 \\
\hline
\end{tabular}

with depression (Stern et al., 1999). In other words, whether medication referrals are made and how professionals view interprofessional communication impact treatment quality and care. This result begs the question: How do MFTs view the use of psychotropic drugs as an adjunct to treatment?

\section{METHOD}

It is clear from the Hernandez and Doherty (2005) study that psychotropic use is a growing reality for MFTs. Therefore, the overall goal of this study was to identify the attitudes and beliefs of clinical members of the American Association for Marriage and Family Therapy (AAMFT) regarding psychotropic drugs.

The study addressed three research questions:

1. How willing are MFTs to identify medication as a realistic treatment option?

2. What attitudes do MFTs have regarding psychotropic medication?

3. How willing are MFTs to refer clients for medical evaluations?

\section{Sample}

Participants were selected by means of a randomized multi-staged clustering sample technique. This technique entailed randomly selecting licensed clinical members of AAMFT throughout the United States. A total of 1,953 clinical members of AAMFT were solicited to participate in the study, of which 1,720 emails successfully reached the potential participants. A total of 322 participants completed the survey, for an $18.7 \%$ response rate. This response rate, while lower than desired, was similar to other Internet surveys, which had response rates ranging from 20\% to $29 \%$ (Deutskens, Ruyter, Wetzels, \& Oosterveld, 2004; Kaplowitz, Hadlock, \& Levine, 2004). The final sample consisted of clinical members of AAMFT ranging in age from 28 to 78 years, with the mean age being 52.6 years. In addition, $42.5 \%$ of the participants were male and $57.5 \%$ were female. Other demographic information is found in Table 1. 


\section{Procedures}

The Dillman (2000) method, which outlines effective Internet survey designs, was used. Based on this method, a total of four contacts were prepared to maximize response rates: (a) brief prenotice email, (b) invitation to study with informed consent and link, (c) follow-up contact email, and (d) final email reminder. However, step four was not implemented because a sufficient sample size was obtained after step three to run the statistical analysis. It is believed that a higher response rate would have been achieved had step four been completed.

Procedures for this study followed a two-step process. First, participants were required to read a hypothetical clinical vignette about a couple presenting to therapy with multiple stressors and then were asked questions about the vignette. Second, they were asked a variety of questions aimed at assessing their knowledge and attitudes toward psychotropic medications and collaborative health care practices. The clinical vignette contained several factors suggesting that one of the clients may be experiencing a major depressive episode (see the appendix). Similar to past vignettes (Dersch, 2002), which highlighted specific indicators of a clinical problem, this study's clinical vignette was based on the DSM-IV-TR diagnostic criteria for major depressive episodes (American Psychiatric Association, 2000a).

\section{Validity}

To ensure that the clinical vignette had adequate construct validity, the authors consulted a multidisciplinary group that could make a reasonable decision about the face and content validity of the vignette. This group included licensed MFTs, psychiatry residents, and a licensed professional counselor. In addition, students in a marriage and family therapy program were also invited to read the vignette and provide feedback. In doing so, our first intention was to obtain consensus from this group that the vignette accurately presented a client experiencing a major depressive episode. Second, we wanted to know if clinicians with a minimum of a master's degree would recognize and diagnose the clinical vignette without difficulty. We received consensus from these participants that served to validate this clinical vignette.

\section{Questions}

After reading the case vignette, the participants answered two open-ended questions designed to assess whether or not they identified depression as a significant issue, and how they would respond to the presenting problem (Dersch, 2002).These questions included the following:

- "What is the most clinically significant issue in this scenario?"

- "What action(s) would you take/intervention(s) would you use to help this couple?"

The authors selected these questions because they neither lead the participant in any direction nor revealed the purpose of the study. Instead, they allowed the therapists to identify what they believe are the most salient issues (Dersch, 2002).

The second portion of the questionnaire contained demographic questions about gender, ethnicity, age, highest degree obtained, theoretical orientation, and personal experience with psychotropic medications. The final portion of the survey focused on participants' attitudes and beliefs regarding medication, as well as their beliefs about collaborative practices with physicians in coordinating care.

\section{Scale Development}

As with the case vignette, the authors found it necessary to independently develop a scale for attitudes about medication use, as no previous scale existed at the time. Consequently, the authors contacted clinicians and researchers who could make a reasonable decision about the content validity of the scale. These individuals included psychiatry residents, licensed clinicians, and researchers who work in hospital and university settings. The result of this collaborative effort led to the development of a 43-question Likert-type scale containing questions in eight subscales. The following are the reliability scores for each subscale:

Knowledge. Six statements were used to assess clinicians' knowledge regarding psychotropic medications. Examples of these statements included "I lack knowledge about psychotropic medications" and "I know how to do therapy with individuals who take prescribed medication." The reliability analysis resulted in a Cronbach's alpha of .71. 
Attitudes. Eighteen statements were used to assess clinicians' attitudes about medication. A higher score on this scale indicated that a participant had more negative attitudes toward medication use. Examples of these statements included "I prefer not to work with clients who are taking psychotropic medications," "The benefits of psychotropic medication are temporary," and "People who take psychotropic medications are emotionally weak." A reliability analysis of this subscale resulted in a Cronbach's alpha of .87.

Effects of drugs. Three statements assessed clinicians' knowledge of side effects of psychotropic medications. Examples of these statements included "I know which psychotropic medications are addictive" and "I would be able to recognize if my client is abusing their psychotropic medication." A reliability analysis of this subscale resulted in a report of internal consistency producing a Cronbach's alpha of .65.

Personal experience. Four statements assessed clinicians' personal experience with medication. Examples of these statements included "I have seen positive results in therapy when working with clients who are taking psychotropic medications" and "I have family members who use psychotropic medications." The Cronbach's alpha for this subscale was .70.

Medication adherence. Four statements assessed clinicians' beliefs and attitudes about their role in medication adherence. Examples of these statements included "It is important to talk to my clients about whether they take their medication as prescribed" and "I spend time in therapy talking with my clients about adherence to their psychotropic medication." A reliability analysis of these statements resulted in a Cronbach's alpha of .72.

Referral/ collaboration. This scale was composed of three statements assessing clinicians' attitudes about collaborating with a physician. These questions included "I can collaborate the therapy treatment and the psychotropic medication use of my client successfully with a physician," "I have had positive experiences collaborating with my clients' treatment with that of their physicians," and "I am intimidated when I have to work with a physician." A reliability analysis of these statements resulted in a Cronbach's alpha of .75.

Clinicians' distrust of physicians. Three statements assessed whether clinicians trusted physicians. Higher scores on this scale indicated a higher degree of distrust of physicians. These statements included "I am concerned that when I refer a patient for psychotropic medication consultation, that the physician will undermine my work," "Physicians are less likely to value therapy," and "Physicians will value psychotropic medications more than therapy." The Cronbach's alpha for this subscale was .79.

Referral knowledge. Two statements assessed clinicians' knowledge of referral sources: "I know a referral source where I can get more information about psychotropic medication" and "I know where I can refer my clients for psychotropic medication." A reliability analysis of these questions resulted in a Cronbach's alpha of .82.

Data analysis. This study employed logistic regression as it is the best choice to predict a dichotomous dependent variable on the basis of continuous and/or categorical independent variables (Garson, 2006; Rice, 1994). Logistic regression was also appropriate because the initial phase of this study served to (a) identify whether therapists recognized and diagnosed depression in the vignette and (b) categorize how therapists reacted to indicators of depression. Responses were coded and then run against the continuous and/or categorical independent variable to determine the odds of an independent variable increasing or decreasing, based on a one-unit increment of the dependent variable. All results were presented in the form of odds ratios, with odds defined as the probability of an event divided by the probability of no event (Reifman, Barnes, Dintcheff, Farrell, \& Uhteg, 1998).

\section{RESULTS}

\section{Depression Logistic Regression}

The first logistic regression looked at what factors predict the identification of depression as the "most clinically significant issue" in the clinical vignette. Table 2 presents these results. Responses were coded categorically with therapists receiving a score of "one" if "depression" was specifically mentioned, and "zero" if not. 
Table 2. Logistic Regression: Recognition of Depression

\begin{tabular}{lllllll}
\hline & B & SE & Wald & DF & Sig. & OR \\
\hline $\begin{array}{l}\text { Block 2 } \\
\text { Attitude }\end{array}$ & -0.883 & 0.428 & 4.266 & 1 & $.039^{*}$ & 0.413 \\
\hline
\end{tabular}

Only significant variables are reported in the above table.

$* p \leq .05$

Table 3. Logistic Regression: Recognition of Medication Referral

\begin{tabular}{|c|c|c|c|c|c|c|}
\hline Variable & B & $S E$ & Wald & DF & Sig. & OR \\
\hline \multicolumn{7}{|l|}{ Block 1: Demographic } \\
\hline $\begin{array}{r}\text { Training in psychopharmacology } \\
(0=\text { university class, } 1=\text { other })\end{array}$ & -0.778 & 0.361 & 4.641 & 1 & $.031^{*}$ & 0.459 \\
\hline $\begin{array}{l}\text { Since graduation, have you } \\
\text { become more knowledgeable } \\
\text { about psychotropic drugs? } \\
(0=\text { no, } 1=\text { yes })\end{array}$ & 2.170 & 1.083 & 4.013 & 1 & $.045^{*}$ & 8.760 \\
\hline \multicolumn{7}{|l|}{ Block 2: Attitude } \\
\hline Attitude & -1.132 & 0.383 & 8.729 & 1 & $.003^{*}$ & 0.322 \\
\hline Effects of drugs & 0.604 & 0.295 & 4.187 & 1 & $.041^{*}$ & 1.829 \\
\hline Medication adherence & -0.821 & 0.326 & 6.340 & 1 & $.012^{*}$ & 0.440 \\
\hline
\end{tabular}

Only significant variables are reported in the above table.

$* p \leq .05$

Attitudes about psychotropic medication. Only one independent variable was significant in increasing the odds of one making a medication referral, one's "attitudes" regarding psychopharmacology. This variable was significant at the .039 level (see Table 2). In this model, the fact that the odds ratio was below 1.0 (0.413) indicates that a high score or one-unit increment on "Attitudes" (suggesting more negative attitudes toward medication use) is associated with lower odds of identifying depression in the scenario. In other words, clinicians with negative attitudes toward medication use were less likely to identify depression in the scenario.

\section{Medication Referral Logistic Regression}

A logistic regression was also necessary to identify what factors would predict the identification or recognition of medication referral among the participants. Responses were coded categorically with therapists receiving a score of "one" for therapists who specifically mentioned "medication referrals" as an action or intervention that they would take and "zero" if not. Upon analysis several independent variables were shown to increase one's odds of making a medication referral. Table 3 presents the results of this analysis.

Training in psychopharmacology. The results also showed that one's training received in graduate school, such as having a dedicated university class on pharmacology [0], versus "other" [1] (e.g., pharmacology was briefly mentioned in a class, in a workshop, or during clinical supervision), was significant at the .031 level. In this model, the fact that the odds ratio was below $1.0(0.459)$ indicates that a higher score on 
Table 4. Regression: Attitudes about Medication

\begin{tabular}{|c|c|c|c|c|}
\hline Variable & $\mathrm{B}$ & $S E$ & $\mathrm{~b}$ & $p$ \\
\hline \multicolumn{5}{|l|}{ Block 1: Demographic } \\
\hline Gender $(0=\mathrm{M}, 1=\mathrm{F})$ & -0.114 & 0.056 & -0.119 & $.043^{*}$ \\
\hline $\begin{array}{l}\text { Highest degree earned } \\
(0=\text { Master's, } 1=\text { Doctorate })\end{array}$ & -0.131 & 0.061 & -0.134 & $.032^{*}$ \\
\hline $\begin{array}{l}\text { What percentage of your clients } \\
\text { are on psychotropic medication? }\end{array}$ & -0.004 & 0.001 & -0.195 & $.001^{* *}$ \\
\hline $\begin{array}{l}\text { I have taken psychotropic drugs } \\
\text { at one point in my life } \\
(0=\text { no, } 1=\text { yes })\end{array}$ & -0.184 & 0.056 & -0.191 & $.001^{* *}$ \\
\hline \multicolumn{5}{|c|}{ Demographics: $R^{2}=.133^{* *}, F(10,280)=4.29, p<.001$} \\
\hline \multicolumn{5}{|l|}{ Block 2: Attitude } \\
\hline Knowledge & -0.363 & 0.053 & -0.438 & $.001^{* *}$ \\
\hline Personal experience & -0.224 & 0.038 & -0.328 & $.001^{* *}$ \\
\hline Distrust of physicians & 0.133 & 0.027 & .236 & $.001^{* *}$ \\
\hline
\end{tabular}

Increment from adding second block (Attitude subscale): $\mathrm{D} R^{2}=.348^{* *}, F(7,273)=26.17, p<.001$

Cumulative of both blocks: $R^{2}=.481, F(17,273)=14.88, p<.001$

Coefficients are standardized.

Only significant variables are reported in the above table.

${ }^{*} p \leq .05 ;{ }^{* *} p \leq .001$

"other" type of training is associated with lower odds of making a medication referral. In other words, clinicians who did not have a dedicated university class in psychopharmacology were less likely to make a medication referral.

Becoming more knowledgeable about psychotropic medication. Therapists who actively became more knowledgeable about psychopharmacology since they graduated (no [0] vs. yes [1]) was statistically significant at the .045 level. Having an odds ratio above 1.0 (8.760) indicates that a higher score (becoming more knowledgeable since graduation) is associated with higher odds of making a medication referral.

Attitudes about psychotropic medication. Having more negative attitudes about medication was significant at the .003 level. An odds ratio below 1.0 (0.322) indicates that a high score on "Attitudes" (suggesting negative attitudes toward medication use) is associated with lower odds of making a medication referral.

Understanding the effects of psychotropic medication. This independent variable was statistically significant at the .041 level. In this model, the odds ratio was greater than 1.0 (1.829), indicating that higher scores on "Effects of Drugs" are associated with higher odds of making a medication referral.

Medication adherence. Finally, understanding the importance of medication adherence was significant at the .012 level. This odds ratio was less than 1.0 (0.440), indicating that higher scores on "Medication Adherence" are associated with lower odds of making a medication referral.

\section{Regression Analysis on Subscales}

Because part of this study's overall goal was to assess attitudes about medication use among clinical members of AAMFT, an additional regression analysis served to identify what variables most likely pre- 
dict positive or negative attitudes about medication use, with the "Attitude subscale" as the dependent variable. Two blocks analyzed what variables predict attitudes about medication use. The first block included the appropriate demographic variables, such as Gender, Age, and Highest Degree Obtained. (See Table 4 for an explanation of variation in the dependent variable, "Attitudes subscale," relative to demographic variables.)

The second block analyzed the subscales of "Knowledge," "Effects of Drugs," "Personal Experience," "Medication Adherence," "Referral/Collaboration," "Distrust of Physicians," and "Referral Knowledge" to identify which subscales predicted or accounted for variation in the Attitudes subscale.

All steps of the regression or the overall model were significant. The demographic block (Block 1) alone was significant, the incremental addition of Block 2 (Attitude subscales) was significant, and the cumulative (both blocks) was also significant (see Table 4). The overall model accounted for $48.1 \%$ of variance in attitudes about medication use.

\section{Block 1}

In the first block, the independent variables served as predictors of attitudes about medication use. Regression results indicated an overall model of four predictor variables (gender, highest degree obtained, percentage of clients on psychotropic medication, and personally having taken psychotropic medication) that significantly predicted attitudes about medication use in therapy (see Table 4). For reasons of parsimony, and in an attempt to reduce repetitive statistical jargon, a more detailed interpretation of statistical results among significant predictors will only be provided for the predictor variables gender and highest degree obtained.

Gender. The variable "Gender" was statistically significant at the .043 level. This means that with every one-unit increment on Gender, there was a negative -.114 relationship with negative attitudes toward medication use in therapy, suggesting that female clinicians had more positive attitudes toward medication use than male clinicians.

Highest degree obtained. The variable "Highest degree obtained" (master's vs. doctorate degree) was significant at the .032 level. This means that with every one-unit increment on degree obtained, there was a negative -.131 relationship with negative attitudes toward medication use. In other words, clinicians with doctorate degrees had more positive attitudes toward medication use than clinicians with master's degrees.

Percentage of clients on psychotropic medication. The variable "Percentage of clients on psychotropic medication" was significant at the .001 level. Consequently, clinicians with a higher percentage of clients on psychotropic medication had more positive attitudes regarding medication use.

Personally having taken psychotropic medication. Finally, "personally having taken psychotropic medication" was significant at the .001 level. Therefore, having taken psychotropic medication is a significant predictor of positive attitudes about medication use.

\section{Block 2}

Independent variables in the second block (knowledge, effects of drugs, personal experience, medication adherence, referral/collaboration, distrust of physicians, and referral knowledge) were predictors of attitudes about medication use. Regression results indicated an overall model of three predictor variables (knowledge, personal experience, and distrust of physicians) significantly predicting attitudes about medication use (see Table 3).

Knowledge. The variable "Knowledge" was significant at the .001 level. This finding suggests that the more knowledge that clinicians think they have about psychotropic medications, the more positive their attitudes will be regarding medication use.

Personal experience. This variable was significant at the .001 level. This suggests that clinicians with more positive personal experiences with medication use also had more positive attitudes regarding medication use.

Distrust of physicians. Finally, a therapist's overall "Distrust of Physicians" was significant at the .001 level. In other words, clinicians who distrusted physicians were more likely to have negative attitudes regarding medication use. 


\section{DISCUSSION}

\section{Identifying Depression}

Surprisingly, 26\% (26.4\%) of participants did not recognize depression as the "most clinically significant issue" to be addressed in the vignette. This result was unexpected for several reasons. First, the clinical vignette was designed so that all clinicians would be able to readily identify depression as a clinical concern. In fact, the authors went to great lengths to solicit feedback from psychiatry residents, PhD-level clinicians, and students in training to ensure that the vignette would be easily identified as depression. Second, all participants were licensed clinicians in their respective states, held a minimum of a master's degree, and were AAMFT clinical members. As a result, it was assumed that participants had received adequate training in diagnosis on a number of mental health disorders, specifically those that represent a major portion of clinical presenting problems.

One possible explanation for this finding is that clinicians may feel that diagnosing a client with depression stigmatizes the client further, and that "diagnoses" are not helpful in the therapeutic process (Gergen, Hoffman, \& Anderson, 1996). Second, the study's methodology may not have allowed clinicians to address all the issues that they felt were important prior to identifying depression. This may be true because depression was not "explicit" in the scenario, and respondents may have wanted to explore other options first (Dersch, 2002). This may have led clinicians to not identify depression in the clinical vignette until further assessments could be made, when in actuality they would have reached this conclusion eventually.

One factor was most significant in the identification of depression as a clinically significant issue in therapy: clinicians' attitudes about medication use. Specifically, clinicians with more positive attitudes about medication use were more likely to identify depression in the clinical vignette. This suggests that clinicians with positive attitudes toward medication use may be more in tune with mental health problems that are treated psychopharmacologically. As a result, they can more readily recognize symptoms of depression and gauge its severity level.

\section{Medication Referral}

Only $35.7 \%$ of all participants specifically stated that they would suggest a "medication referral" as an "action or intervention" to help this individual experiencing a major depressive episode. This finding has important implications for the field of marriage and family therapy, suggesting that clinical members of AAMFT may still be uncertain about recognizing medication as a viable treatment option in therapy, even for more severe clinical cases. In fact, evidence-based research indicates strong support for combined treatment approaches (e.g., medication and psychotherapy), especially for clients with moderate to severe depression (Pampallona, Bollini, Tibaldi, Kupelnick, \& Munizza, 2004; Reynolds et al., 1999; Thase et al., 1997). Other studies have shown that combined treatment is effective for clients with less severe depression, as well as for those with severe, recurrent depressive episodes (Thase et al., 1997).

While this finding is significant, one factor may contribute to why clinicians did not explicitly state "medication referral" as a plausible treatment option. First, clinicians may have felt uncomfortable with an a priori assessment issue, such as diagnosing one partner only when the couple had come for therapy. This may have posed a challenge for clinicians, as their general systems perspective would have conflicted with a nonsystemic perspective of diagnosing and referring an individual for medication in a couple therapy context. Consequently, many clinicians may have felt a need to further assess the couple and their functioning prior to making a medication referral, and therefore did not yet view this as a possible treatment option.

Even in light of this factor, the results should give us some pause for concern, as they have particular relevance for MFT educators and trainers. This is especially true in light of the fact that clinicians with a "dedicated university class" in psychopharmacology were more likely to identify medication as a viable treatment option.

In addition, this finding may suggest that clinical members of AAMFT lack adequate training in psychopharmacology. This statement seems supported by the fact that only $17.2 \%$ of clinical members surveyed reported taking a dedicated university class in psychopharmacology as part of their graduate training. These findings also raise the question of whether clinicians have access to or actively educate 
themselves concerning the most recent literature on best practices supporting the efficacy of combined treatment approaches, especially for clients who meet the diagnostic criteria for moderate or severe depression (Beitman \& Saveanu, 2005; Thase, 2003). In fact, this study shows that $80.1 \%$ of surveyed AAMFT clinicians reported that they were not adequately trained about psychotropic medications in their graduate programs. Patterson, Albala, McCahill, and Edwards (2006) further provided support for why therapists fail to refer clients for medication evaluations, arguing that it is related to their lack of knowledge about science. As a result, a lack of knowledge about science may add to feelings of distrust about the effects of medication, creating uncertainty about the utility of a medication referral. Consequently, MFTs may not be referring patients when appropriate, in essence withholding efficacious treatment unknowingly, possibly failing our clients (Patterson et al., 2006).

In addition, these findings have relevance for current practicing clinicians as an indicator of future growth areas. This is especially true for clinicians who have received little or no training in psychopharmacology and are not actively seeking knowledge in this area. In fact, results suggest that clinicians who actively "became more knowledgeable about psychotropic medications after their graduate programs" were more likely to identify "medication referral" as a treatment option. The results of this study confirm that clinical years of practice are not predictive of medication referrals. Rather, clinicians' individual efforts to self-educate regarding psychopharmacology after graduation, either through CE workshops or personal research, increase the likelihood of medication referrals. As a result, it may be beneficial for clinicians to actively take CE workshops on psychotropic medications at AAMFT or other equivalent conferences.

Three specific variables on the "Attitudes About Medication Use Scale" were also predictive of clinicians' identifying medication as a viable treatment option. Not surprisingly, a negative attitude toward medication use was a significant predictor of not identifying medication as a viable treatment option. Therefore, clinicians' individual attitudes about medication use clearly impact whether or not they make medication referrals. This result suggests potential ethical concerns, especially in light of recent research that shows that combined treatment (e.g., medication and psychotherapy) is the most effective when working with clients with serious mental health problems. One may question whether therapists are acting ethically if they fail to recommend a medication consultation for their clients, especially if they meet criteria for a more severe mental health disorder that has been proven to be effectively treated with medication and psychotherapy. Future studies are suggested to identify what factors influence clinicians' attitudes about medication use. This could ultimately provide helpful information on what efforts can be made to increase understanding of the role of medication referrals in therapy.

Next, participants who understood the effects of psychotropic medications were much more likely to refer their clients for a medication evaluation. This suggests that knowledge about psychotropic medications and their potential side effects may be an important component in the decision to make a medication evaluation referral. This further provides evidence that education and knowledge about psychopharmacology within training programs play an important role in whether medication referrals occur.

Finally, clinicians who recognized the importance of monitoring medication adherence throughout treatment were much less likely to make a medication referral. This finding was surprising, contradicting the assumption that clinicians who recognize the importance of monitoring medication use would be much more likely to make a medication referral. One factor may play a significant role in why this is true, as clinicians may feel that monitoring medications detracts too much of their time away from therapy. Therefore, their attitudes about the benefits of medication use may outweigh the benefits of taking the necessary time to encourage clients to continue their treatment, as recommended by their physician. Future research may benefit in studying this phenomenon more closely.

\section{Regression Analysis on Subscales}

The results of the final regression show that several independent variables (e.g., gender, highest degree obtained, personally having taken psychotropic medication, knowledge about psychotropic medications, personal experience, and distrust of physicians) were predictive of more positive attitudes about 
medication use among clinical members of AAMFT. First, women were more likely to have more positive attitudes about medication use than men. This result, while not linked to a specific research hypothesis, validates other studies suggesting that female clinicians are much more likely to collaborate with physicians on their clients' mental health care and to advocate a greater belief in the biopsychosocial model then men (Gavin et al., 1998). It could also be related to gender socialization in help-seeking behaviors between men and women (Noone \& Stephens, 2008). A growing body of literature suggests that women use more health care services than men and are more likely to seek help, often from multiple sources, to address their physical, mental, and emotional concerns (Galdas, Cheater, \& Marshall, 2005). Consequently, it could be that because women use more health care services than men, they have more positive attitudes about their clients utilizing the full range of medical care available to them.

Next, clinicians who possessed a doctorate, as opposed to a master's degree, were more likely to have positive attitudes about medication use: $t(2.15), p<.03$. This finding may point to the benefits that clinicians gain with additional educational opportunities or knowledge in this arena. This may be tied to the fact that doctoral students may have more opportunities to learn about medication issues through a class or supervision while still in their training programs. In addition, doctoral students may possess more knowledge about evidence-based practices as a result of their involvement in research.

Another important variable was the percentage of their clients on "some sort of psychotropic medication." According to the final regression, there is a positive relationship between having a greater percentage of a clinician's clientele on medication and more positive attitudes regarding medication use. Several reasons may explain this finding. First, clinicians with more clients on psychotropic medication may have seen more benefits of medication use than those with fewer patients on psychotropic medications. Also, clinicians with more clients on medication may take more time to educate themselves about psychopharmacology, recognizing its benefits and side effects. Unfortunately, this study does not indicate whether participants' clients were already taking psychotropic medications upon entering therapy, or if they were referred for medication consultations by their clinicians. Future studies should be done to understand the referral patterns of MFTs regarding psychotropic medications. Such research would be particularly relevant, given that on average, clinicians reported that nearly $47.8 \%$ of their clientele took some sort of psychotropic medication. In other words, $98 \%$ of clinicians reported having clients on psychotropic medication, accounting for nearly half of their caseload. This finding is substantially larger than that reported by Hernandez and Doherty (2005); in the latter study, the researchers found that $91 \%$ of clinicians had clients on psychotropic medication, accounting for nearly a quarter of their caseloads.

It is clear, based on the substantial increase of clients on psychotropic medications from past studies (Hernandez \& Doherty, 2005), that medication use for many clients experiencing a mood disorder is now the norm, as opposed to an anomaly. In fact, physicians are becoming more involved in the treatment of mental health problems with medication as the first choice of treatment (Olfson et al., 2002), as they are prescribing these medications at a higher rate. Consequently, MFTs might not know whether their clients are using psychotropic medication because they do not ask, and their patients do not think it is important to mention.

In addition, with the growing drug advertisements to the general public, on the television and in popular periodicals, it may be safe to assume that the public is as knowledgeable about medication as MFTs. It is plausible that clients are searching out medication as a first-line defense and then pursuing multiple venues to treat their mental health problems, until their symptoms are resolved (Kessler et al., 1999). Consequently, regardless of MFTs' attitudes about medication use, coordinating treatment with other medical health care providers, and educating oneself regarding psychotropic medication use, may be a critical component in providing quality care to one's clients.

The results of this study also found that clinicians who have taken psychotropic medications at one point in their lives would have more positive attitudes about medication use. Therefore, it would seem that personally taking psychotropic medication might decrease any stigmatization that clinicians may 
have about psychotropic medication. In addition, the "Personal Experience" subscale (i.e., seeing the positive impact of medication use in the lives of clients or family members) was also predictive of more positive attitudes about medication use. While these results were very interesting, the large number of clinicians who reported having taken psychotropic medication at one point in their life may be surprising to some. Nearly $39.2 \%$ of the clinicians participating in this study had taken psychotropic medications at some point in time.

Finally, clinicians' attitudes about physicians seem to be an important predictor in whether they have positive or negative attitudes about medication use. Results of this regression found that if clinicians believe that physicians do not value their work, or will undermine their work, they will also have more negative attitudes about medication use. This suggests that negative beliefs about physicians and physicians' views of therapy may cause clinicians to form less favorable attitudes toward medication use. Other research supports this finding, indicating that clinicians and physicians do a poor job in collaborating care with their clients, which may result from the misconceptions and fears that professionals have regarding one another (Klerman, 1993; Patterson \& Magulac, 1994). In fact, only 10.2\% of the sample reported collaborating care with a physician during the entire time their client is under the physician's care, and only $36.6 \%$ contact the physician prior to sending the referral to a physician.

\section{Limitations}

While this study provides important information for the MFT field, it is not without its limitations.

Self-report. The first and probably most obvious limitation of this study is that it is entirely based on self-report. As a result, these findings only include what respondents are willing to share. Second, while participants were initially blind to the purpose of the study to account for social desirability, this factor cannot be entirely controlled. Consequently, it is still possible that once participants became aware of the purpose of the study, in later portions of the questionnaire, that they may have inflated their responses to appear more competent or knowledgeable about psychotropic medications.

Measurements. Another limitation of this study is the instrument. Because no scales exist in the literature about clinicians' attitudes regarding psychotropic medications, the authors had to develop the scales. As a result, none of the measures used in the study came from previously tested assessments. Consequently, the validity of the findings may be held in question until further studies can validate these scales. Despite this limitation, it is important to recognize the great lengths to which the authors went to get feedback and advice from professionals in the field to develop the best measure possible. In addition, the measures ultimately demonstrated sound psychometric properties once subjected to standard reliability testing procedures.

Sample. Because the entire sample consisted of clinical members of AAMFT, generalizing the findings to other fields should be done with caution. In addition, the sample was almost exclusively made up of Anglo participants, and as a result, the sample may only be generalizable to Anglo clinicians. Future studies should work to identify attitudes and beliefs held by clinicians of other ethnicities.

Internet data collection. Another limitation of this study is the fact that data were collected entirely by means of the Internet. While this provided a practical, efficient, and cost-effective means of dispersing the questionnaire, it may have excluded a group of clinicians from responding. This may be true in the case of clinicians who are not computer or Internet literate, as well as clinicians who do not use the Internet in their practice.

Respondent bias. Another limitation of this study is the potential for responder bias. In other words, participants who chose to take part in the study may be different from those who did not. For example, the mean age of clinicians in this study was 53 years of age. Consequently, seasoned clinicians may have been less likely to identify medication referral as a viable treatment option, as training programs in the 1970s, 1980s, and 1990s were not required to teach psychopharmacological treatments. This is evident in the fact that it was not until 2001 that the COAMFTE standards changed to require psychopharmacological treatments be taught. Therefore, this sample may not accurately represent the entire field of MFT. 
Response rate. While the number of participants in this study is relatively high, the response rate in this study was lower than desired (around 19\%). Consequently, this sample may not be a true representation of the entire field of MFT, as it may be a nonrepresentative sample. Therefore, generalizability of these findings should be made with caution.

Correlation data. A final limitation of this study is the inability of logistic and regular regression to ascertain causality. Consequently, the results presented can only ascertain relationships among variables. For example, one of the results of the study suggests that there is a positive relationship of "having personally taken psychotropic medication" and one's having more favorable attitudes about psychotropic medication. It may be just as plausible that one has favorable attitudes about psychotropic medication that leads one to "have personally taken psychotropic medication."

\section{Future Research}

Clearly, a need for further investigation exists to understand the attitudes and beliefs of clinicians regarding psychotropic medication. While this study provides important data on what factors lead clinicians to be more likely to make a medication referral, it cannot capture all contributing factors regarding clinicians' attitudes, beliefs, and referral practices regarding psychotropic medications. As a result, future qualitative and quantitative research would add tremendously to this literature, helping to ascertain the developmental processes that MFT clinicians undergo in forming their attitudes and beliefs regarding psychotropic medications.

In addition, qualitative data in future studies could adequately account for when AAMFT clinicians view medication referrals as appropriate, and at what point they first mention this topic with clients. This would allow researchers to better understand the process that clinicians undergo in identifying when it is suitable to make medication referrals. In fact, the results from this study indicate that taking a formal course in psychopharmacology played a significant role in participants' positive attitudinal development and odds of making a medication referral. It would therefore be interesting to identify what role this formal course plays in clinicians' attitudes and beliefs regarding psychotropic medication and compare these experiences to those of clinicians who did not have a formal course.

Next, replications of this study would further develop a reliable and valid instrument in looking at clinicians' attitudes and beliefs regarding psychotropic medication. Validating the measures used in this study would add significantly to the field, as no validated measure currently exists for this phenomenon. In addition, replications of the study would provide other researchers the opportunity to study this phenomenon, and to discover more about how clinicians' attitudes and beliefs about medication use change over time.

Future studies could also compare attitudes and beliefs of MFTs with those of clinicians in other disciplines, such as psychology, social work, and counselor education. These investigations would provide invaluable information about which disciplines have more positive attitudes about psychotropic medication use, and which are more open to collaboration with physicians in coordinating behavioral health care. In addition, such studies could serve to explain what aspects of training programs in different disciplines lead to these attitudes and beliefs, as well as the implementation of evidence-based practices.

Finally, future studies should aim to identify whether or not MFT programs are currently teaching evidence-based practices regarding psychotropic medication use. Evidence-based practices must be at the core of clinical programs and will provide clinicians with the needed tools to successfully refer, work with, and treat their clients who could benefit from more specific medical interventions that lie outside the typical scope of marriage and family therapy.

\section{REFERENCES}

Agency for Health Care Policy Research. (1993). Depression Guideline Panel. Depression in primary care. Volume 2: Treatment of major depression. Rockville, MD: U.S. Department of Health and Human Services, Public Health Service, Agency for Health Care Policy and Research. 
American Psychiatric Association. (2000a). Diagnostic and statistical manual of mental disorders (4th ed., text revision). Washington, DC: APA.

American Psychiatric Association. (2000b). Practice guideline for the treatment of patients with major depressive disorder (revision). American Journal of Psychiatry, 157(4), 1-45.

Baucom, D. H., Shoham, V., Mueser, K. T., Daiuto, A. D., \& Stickle, T. R. (1998). Empirically supported couple and family interventions for marital distress and adult mental health problems. Journal of Consulting and Clinical Psychology, 66, 53-88.

Beitman, B. D., Blinder, B. J., Thase, M. E., Riba, M., \& Safer, D. L. (2003). Integrating psychotherapy and pharmacotherapy: Dissolving the mind-brain barrier. New York: W. W. Norton.

Beitman, B. D., \& Saveanu, R. V. (2005). Integrating pharmacotherapy and psychotherapy. In J. C. Norcross \& M. R. Goldfried, eds., Handbook of psychotherapy integration (pp. 417-436). New York: Oxford University Press.

Dersch, C. (2002). Therapist reactions to treating cases of partner violence. Unpublished doctoral dissertation, Texas Tech University.

Deutskens, E., Ruyter, K. D., Wetzels, M., \& Oosterveld, P. (2004). Response rate and response quality of Internetbased surveys: An experimental study. Marketing Letters, 14(1), 21-36.

Dillman, D. A. (2000). Mail and Internet surveys: The tailored design method. New York: John Wiley \& Sons.

Engel, G. (1977). The need for a new medical model: A challenge for biomedicine. Science, 196, 129-136.

Friedman, M. A., Detweiler-Bedell, J. B., Leventhal, H. E., Home, R., Keitner, G. I., \& Miller, I. W. (2004). Combined psychotherapy and pharmacotherapy for the treatment of major depressive disorder. Clinical Psychology: Science and Practice, 11, 47-65.

Galdas, P. M., Cheater, F., \& Marshall, P. (2005). Men and health help-seeking behavior: Literature review. Journal of Advanced Nursing, 49, 616-623.

Garson, G. D. (2006). Logistic regression. Retrieved October 10, 2006, from http:/ / -www2.chass.ncsu.edu.library.unl. edu/garson/pa765/logistic.htm

Gavin, L. A., Wagers, T. P., Leslie, B., Price, D., Thorland, W., \& Stulp deGroot, C. (1998). Medical and mental healthcare providers' attitudes about collaboration. Families, Systems $\mathcal{E}$ Health, 16(1/2), 139-146.

Gergen, K. J., Hoffman, L., \& Anderson, H. (1996). Is diagnosis a disaster? A constructionist trialogue. In F. W. Kaslow, ed., Handbook of relational diagnosis (pp. 102-118). New York: John Wiley.

Haley, J. (1989). The effects of long-term outcome studies on the therapy of schizophrenia. Journal of Marital and Family Therapy, 15, 127-132.

Hernandez, B. C, \& Doherty, W. J. (2005). Marriage and family therapists and psychotropic medications: Practice patterns from a national study. Journal of Marital and Family Therapy, 31, 177-189.

Jackson, D. D. (1967). Aspects of conjoint family therapy. In G. H. Zuk \& I. Boszormenyi-Nagy, eds., Family therapy and disturbed families (pp. 28-40). Palo Alto, CA: Science and Behavior Books.

Jindal, R. D., \& Thase, M. E. (2003). Integrating psychotherapy and pharmacotherapy to improve outcomes among patients with mood disorders. Psychiatric Services, 54, 1484-1490.

Kaplowitz, M. D., Hadlock, T. D., \& Levine, R. (2004). A comparison of Web and mail survey response rates. Public Opinion Research, 68(1), 94-101.

Kessler, R. C, Zhao, S., Katz, S. J., Kouzis, A. C, Frank, R. G., Edlund, M., et al. (1999). Past-year use of outpatient services for psychiatric problems in national comorbidity survey. American Journal of Psychiatry, 156, 115-123.

Klerman, G. L. (1993). Treatment of depression. In M. Schachter, ed., Psychotherapy and medication: A dynamic integration (pp. 185-198). Northvale, NJ: Jason Aronson.

MacArthur Initiative on Depression and Primary Care. (2009). Depression management tool kit. Retrieved from http:// www.depression-primarycare.org/clinicians/toolkits/materials/form_downloads/

Maggio, L. M., Marcotte, M., Perry, J., \& Truax, D. (2001). Student perspective on family therapy training. Journal of Systemic Therapies, 20(1), 36-44.

Markowitz, L. M. (1991). Better therapy through chemistry. Family Therapy Networker, May/June, 22-31.

McDaniel, S. H., Hepworth, J., \& Doherty, W. (1992). Medical family therapy: A biopsychosocial approach to families with health problems. New York: Basic Books.

McFarlane, W. R., Dixon, L., Lukens, E., \& Lucksted, A. (2003). Family psychoeducation and schizophrenia: A review of the literature. Journal of Marital and Family Therapy, 29, 223-245. 
Miklowitz, D. J., \& Goldstein, M. J. (1997). Bipolar disorder: A family-focused treatment approach. New York: Guilford Press.

Miklowitz, D. J., Simoneau, T. L., George, E. L., Richards, J. A., Kalbag, A., Sachs- Ericsson, N., et al. (2000). Family-focused treatment of bipolar disorder: 1-year effects of a psychoeducational program in conjunction with pharmacotherapy. Biological Psychiatry, 48, 582-592.

Noone, J. H., \& Stephens, C. (2008). Men, masculine identities, and health care utilization. Sociology of Health E Illness, 30, 711-725.

Olfson, M., Marcus, S. C, Druss, B., Elinson, L., Tanielian, T., \& Pincus, H. A. (2002). National trends in the outpatient treatment of depression. Journal of the American Medical Association, 287, 203-209.

Pampailona, S., Bollini, P., Tibaldi, G., Kupelnick, B.. \& Munizza, C. (2004). Combined pharmacotherapy and psychological treatment for depression: A systematic review. Archives of General Psychiatry, 61, 714-719.

Patterson, J. E., Albala, A. A., McCahill, M. E., \& Edwards, T. M. (2006). The therapist's guide to psychopharmacology: Working with patients, families and physicians to optimize care. New York: Guilford Press.

Patterson, J. E., \& Magulac, M. (1994). The family therapist's guide to psychopharmacology: A graduate level course. Journal of Marital and Family Therapy, 20, 151-173.

Pinsof, W. M., \& Wynne, L. C. (1995). The efficacy of marital and family therapy: An empirical overview, conclusions, and recommendations. Journal of Marital and Family Therapy, 21, 585-613.

Reifman, A., Barnes, G. M., Dintcheff, B. A., Farrell, M. P., \& Uhteg, L. (1998). Parental and peer influences on the onset of heavier drinking among adolescents. Journal of Studies on Alcohol, 59, 311-317.

Reynolds, C. F., Frank, E., Perei, J. M., Imber, S. D.( Comes, C, Miller, M. D., et al. (1999). Nortriptyline and interpersonal psychotherapy as maintenance therapies for recurrent major depression: A randomized controlled trial in patients older than 59 years. Journal of the American Medical Association, 281, 39-45.

Rice, J. C. (1994). Logistic regression: An introduction. Advances in Social Science Methodology, 3, 191-245.

Stern, S. L., Williams, T., Dixon, S. L., Clement, J. A" Butt, Z. A., Schwartzbaum, J. A., et al. (1999). Do health professionals' attitudes interfere with the treatment of depression? Depression and Anxiety, 9, 151-155.

Taylor, L. A. (2004). Psychotherapists' practice behaviors related to psychopharmacology (Doctoral dissertation, Alliant International University, 2004). Dissertation Abstracts International, 66, 577.

Thase, M. E. (2003). Conceptual and empirical basis for integrating psychotherapy and pharmacotherapy. In B. D. Beitman, B. J. Blinder, M. E. Thase, M. Riba \& D. L. Safer, eds., Integrating psychotherapy and pharmacotherapy: Dissolving the mind-brain barrier (pp. 111-139). New York: W. W. Norton.

Thase, M. E., Greenhouse, J. B., Frank, E., Reynolds, C. F., Ill, Pilkonis, P. A., Hurley, K., et al. (1997). Treatment of major depression with psychotherapy or psychotherapy-pharmacotherapy combination. Archives of General Psychiatry, 54, 1009-1015.

Van Heden, H. M. (2001). Training for collaboration: A study of medical family therapy interns (Doctoral dissertation, Nova Southeastern University, 2001). Dissertation Abstracts International, 62(2-B), 1103.

Wells, K. B., \& Sturm, R. (1996). Informing the policy process: From efficacy to effectiveness data on pharmacotherapy. Journal of Consulting and Clinical Psychology, 64, 638-645.

\section{APPENDIX}

\section{Clinical Vignette}

Matt and Julie report being happily married for 5 years, but recently have been having difficulties. Matt believes they are having communication problems, but Julie is frustrated and worried about Matt's sudden lack of energy and involvement in their relationship. She reports that Matt's behavior began to change about 2 months ago, when he began to isolate himself from her by going to bed much earlier than she did and sleeping for hours on end. Julie had hoped that it would pass, but over time it had gotten worse. Julie reports that when she tries to talk to Matt about this, he becomes upset and withdraws to the bedroom. In response, Matt complains about just being tired, and wanting to be left alone. He no longer goes out with his buddies, and has even stopped playing golf, something that he thoroughly enjoys. Julie reports that recently Matt has lost some weight, and that he seems to be losing his appetite. Matt reports that eating is a chore and that it is often difficult to concentrate. Julie reports being worried that there might be another woman in Matt's life because he no longer seems interested in having sex with her. Matt denies any extramarital relationships. 